Egyptian Journal of Aquatic Biology \& Fisheries

Zoology Department, Faculty of Science,

Ain Shams University, Cairo, Egypt.

ISSN $1110-6131$

Vol. 25(2): $601-614$ (2021)

www.ejabf.journals.ekb.eg

\title{
Mesoderm Signaling Pathways of Early Development in the Zebrafish Danio rerio
}

Ilham J.J. Alshami* and Hussein A. Saud

Department of Fisheries and Marine Resources, College of Agriculture,

University of Basrah, Iraq

"Corresponding Author: ilham.jalil@uobasrah.edu.iq

\section{ARTICLE INFO}

Article History:

Received: Oct. 20, 2020

Accepted: March 28, 2021

Online: April 23, 2021

Keywords:

BMP,

Nodal,

FGF,

Zebrafish

\section{ABSTRACT}

The zebrafish (Danio rerio) is an ideal fish model for molecular and genetic studies. It is relatively easy to keep in the aquarium and to obtain embryos. The ability to follow embryonic development using microscopic and molecular techniques facilitates the study of mesoderm development. Hence, this study was conducted to investigate the role of four transcription factors that include: bone morphogenetic protein (BMP), nodal, fibroblast growth factor (FGF) and sonic hedgehog $(\mathrm{SHH})$ in mesoderm induction, using specific inhibitors (DM, SB431542, SU5402) and Cyclopamine, respectively. Each inhibitor perturbed mesoderm development and in situ hybridisation, using myllo specific marker for muscles. Results showed noticeable reduction in gene expression with each treatment, indicating a crucial role for all four transcription factors in mesoderm development.

\section{INTRODUCTION}

The mesoderm is one of the three primary germ layers as it forms the muscles during early developing stages. Somites of vertebrates are generated from the paraxial mesoderm (Wang et al.,2019). Muscle cell formation is connected to the expression of a complex set of organizer molecules that arise from one or two major groups of transcription factors (Black \& Olson, 1998; Chin et al., 1998; Allen et al., 2001; Schiaffino et al., 2007; Rana et al., 2008; Gundersen, 2011). In addition, myogenic transcription factors consist of the MEF2 and MyoD groups (Weintraub et al., 1991; Black \& Olson, 1998; Wu et al., 2000; Bassel Duby \& Olson, 2006).

It is worthy to mention that the myogenic regulatory factors (MRFs) are a set of basic helix -loop-helix (bHLH) transcription factors, consisting of myogenin, MRF4, MyoD and MYF5, that have been shown to play a crucial role in the formation of muscle cells (Buckingham, 1992; Arnold \& Brann, 1996; Pownall et al., 2002).

During embryonic development in zebrafish, myoD is initially detected on each side of embryonic shield at 70\%-75\% epiboly (Weinberg et al., 1996). At $80 \%$ epiboly, myf5 
is expressed in two stripes near the notochord (Coutelle et al., 2001). Subsequently, myogenin is expressed during segmentaton period (Weinberg et al., 1996). Remarkably, upstream transcription factors possess an important role in muscle induction, among which PAX7 was reported to play a $\mathrm{n}$ essential has role in the induction of $m y o D$ and myf5 expression in zebrafish (Ochi \& Westerfield, 2007). Fisher et al. (2002) reported the role of FGF signaling in the activation of myoD. T-box transcription factors. Moreover, Ntl and Spt also act as key regulators of myoD expression in zebrafish (Weinberg et al., 1996).

Furthermore, cell fate and tissue development in the embryo is regulated by a small number of key signaling molecules including; fibroblast growth factor (FGF), bone morphogenetic protein (BMP), nodal and sonic hedgehog (SHH). Whereas, bmp is important for dorsal-ventral axis formation (Kudoh et al., 2004). BMP is involved in tail somite, as it expresses at gastrula stage ventrally (Kwon et al.,2010).Additionally, bmp binds to Alk4/5 receptor and activates Smad1/5 and Smad4 leading the ventral specific gene activation at gastrula stage (Mohedas et al., 2013). Notably, the loss of bmp2b in zebrafish results in a swirl mutant phenotype that is characterized by the expansion of neural plate, notochord and somites with reduction of the epidermis and tail (Kishimoto et al., 1997).In addition, snailhouse mutant, that is caused by bmp7 mutation, also results in strongly dorsalised embryo (Dick et al., 2000). It is worthmentioning that Thorimbert et al. (2015) identified DM arrested regeneration in the fin after blastemal formation in the zebrafish.

Thisse and Thisse ( 2005) cited that FGF and nodal contribute in mesoderm induction at early stage of development.In fact, FGF is important in mesoderm and neural induction (Kudoh et al., 2004). Hence, FGF function was detected through blocking it by the chemical inhibitor of SU5402. On the other hand, FGFs genes have 4 receptors, FGFR1, 2, 3 and 4, sending signals via Ras-MapK pathway (Thisse et al., 1995). Thus, it is considered a master regulater for mesoderm signaling. Moreover,the nodal pathway is important for mesoderm and endoderm formation and it can be blocked by SB inhibitor SB505124 (Poulain et al., 2006). Nodal is a member of TGF- $\beta$ family: nodal molecules mediate signals through binding with receptors Alk4, Alk5, and Alk7 that phosphorylate Smad2 and Smad3 (Carcamo et al., 1994; Ryden et al., 1996).

The sonic hedgehog $(s h h)$ signaling is emanated in notochord domain that is important for slow muscle induction (Ochi \& Westerfield, 2007). Additionally, sonic hedgehog codes for SHH protein, and is under the family called hedgehog that also includes desert hedgehog(DHH) and Indian hedgehog(IHH). During embryonic development, Shh binds to patched and smoothened then it is released from patched. Smoothened subsequently initiates downstream signaling, leading the binding of Gli transcription factors to DNA and activates the gene expression (Ochi \& Westerfield, 2007; Lee et al., 2014). Furthermore, Shh in zebrafish is expressed at 50\% epiboly in the 
organizer, and later in the notochord, in the floor plate and ventral brain (Currie \& Ingham, 1996; Ochi \& Westerfield, 2007) . While, hedgehog signaling plays a crucial role in muscle development. In addition, Shh plays a significant role in the patterning of different organs and tissues, including the limbs, skin, spinal cord, lung, hair, eye, somites, CNS, bones and testes ( Hammerschmidt et al.,1997; Murone et al.,1999; Perron et al., 2002; Prykhozhij \& Neumann, 2008). In zebrafish, it was found that blocking of $S h h$, using cyclopamine, results in inhibition of normal differentiation of muscle pioneers that organize the myotome of somite to give the muscle a normal shape (Wolff et al., 2003). Shh signaling that emanate from notochord is important to induce slow muscle (Ochi \& Westerfield, 2007; Lee et al., 2014). These are all important signaling pathways and potentially important for mesoderm development. Hence, by using specific inhibitors of these signaling pathways, the key gene function and signaling pathway involved in the muscle development can be comprehended. Based on this hypothesis, an experimental plan was organized to treat embryos with chemical inhibitors that affect these pathways (DM, Cyclopamine, SU, and SB). Therefore, the aim of current study is to understand the key signaling pathways and molecular mechanisms that regulate mesoderm development .

\section{MATERIALS AND METHODS}

\section{Zebrafish Danio rerio rearing}

Danio rerio were reared in laboratory conditions similar to their natural habitat $\left(28^{\circ} \mathrm{C}, 7.3 \mathrm{pH}\right)$, with water system supplied with oxygen pumps during 24 hours. Dried fry food was given to the larvae, and was replaced with alive artemia after 3 weeks. Cleaning and maintenance were carried out once a week. Fish laid eggs once or twice in a few weeks and deposited eggs in the day. To capture images with details, chorion was enzymatically removed using pronase (Sigma-Aldrich) $(1 \mathrm{mg} / \mathrm{ml}$ in Ringer). Embryos were anaesthetised at $24 \mathrm{hpf}$ with tricaine solution $(0.004 \%)$ and then were photographed. This work was carried out during April 2019.

\section{In situ probe preparation}

One probe was made for in situ hybridization including Dr-myl10. Sp6 and T7 primers that were used for PCR. The PCR products, purified by phenol chloroform extraction, were ethanol precipitated. Antisense RNA probe was synthesized with T7 RNA polymerase (promega) and Dig-RNA labelling mix (Roche).

\section{In situ hybridization staining}

Chorion of D.rerio embryos were removed by pronase (Sigma-Aldrich) $(1 \mathrm{mg} / \mathrm{ml}$ in Ringer) and manually using tweezers. Then, they were fixed in 4\% PFA/PBS and kept at $4^{\circ} \mathrm{C}$ for a minimum period of 5 days for fixation. Samples then were washed with $100 \%$ methanol and stored in $-20^{\circ} \mathrm{C}$ at least for an hour, then washed in PBS tween (PBS, $0.1 \%$ Tween 20) for 10 minutes. PBTW then was replaced with Hyp buffer solution, and the 
embryos were incubated for one hour in $65^{\circ} \mathrm{C}$. Embryos after that were placed in preheated prop/Hyp buffer $\left(90^{\circ} \mathrm{C}\right.$ for 10 minutes and immediately in ice for 5 minutes) then kept in $65^{\circ} \mathrm{C}$ overnight. On the next day, the embryos were washed with a series of buffers : $50 \%$ formamide, $2 \mathrm{X}$ saline-sodium citrate (SSC), $0.1 \%$ tween $2065^{\circ} \mathrm{C}, 30$ minutes ; $2 \mathrm{X} \mathrm{SSC} 0.1 \%$ tween $20 \quad 65^{\circ} \mathrm{C}, 30$ minutes; $0.2 \mathrm{XSSC} 0.1 \%$ tween $20 \quad 65^{\circ} \mathrm{C}, 30$ minutes twice and PBST at RT for 5 minutes. Embryos were blocked in a block solution $+5 \%$ normal goat serum (NGS) for one hour, and replaced by an anti-dig antibody (1/100 dilution of 5000X) for 2 hours. Then, the embryos were washed 4 times each 30 minutes in a shaker, transferred into 24 well plates and treated with AP buffer for 10 minutes. Then, the AP buffer was replaced by BM-purple and kept in a dark box until stained. Finally, a 4\% PFA/ PBS was used to stop staining and fix the embryos.

\section{Treatment of D.rario with chemical inhibitors}

Dorsomorphin (DM) (BMP inhibitor), SB 431542(nodal inhibitor), SU5402(Fgf inhibitor), Cyclopamine (sonic hedgehog inhibitor)) were applied on zebrafish D.rario at $1-2$ cells stage (30 minutes post fertilization) and late gastrula ( $8 \mathrm{hpf}$ ) with DM,1-2 cells stage and sphere stage (4 hpf) with cyclopamine, $1-2$ cells stage and dome stage $\left(4 \frac{1}{2} \mathrm{hpf}\right)$ with SB431542, 1-2cells stage and 50\%epiboly stage (51/4 hpf) with SU5402. The concentrations of DM were: $0 \mu \mathrm{M}$ (control), $5 \mu \mathrm{M}, 10 \mu \mathrm{M}$ and $20 \mu \mathrm{M}$; SB431542 were 0 $\mu \mathrm{M}$ (control), $25 \mu \mathrm{M}, 50 \mu \mathrm{M}$ and $100 \mu \mathrm{M}$; SU5402 were $0 \mu \mathrm{M}$ (control), $10 \mu \mathrm{M}, 20 \mu \mathrm{M}$ and $40 \mu \mathrm{M}$; and cyclopamine were $0 \mu \mathrm{M}$ (control),50 $\mu \mathrm{M}$ and $100 \mu \mathrm{M}$. Three replications were used of each concentration ( 5 embryos in one well). Then, the embryos of D.rerio were cultured in $28^{\circ} \mathrm{C}$ for 24 hours, and chorions were removed by pronase (SigmaAldrich) $(1 \mathrm{mg} / \mathrm{ml}$ in Ringer). Afterwards, photographs were taken using Nikon SMZ1500. The embryos were fixed with 4\%PFA/PBS (5 days) for in situ hybridization. Concentrations in the current study depeded on previous practice experiments, and it was found that the current concentration was more effective.

\section{RESULTS}

\section{Treatment of the zebrafish with chemical inhibitors}

To identify and characterise the key signaling pathways by which mesoderm development is regulated, several inhibitors were tested that block key signaling pathways in early embryonic development. The tested chemicals included: bone morphogenetic protein inhibitor (DM), Fgf inhibitor (SU5402), nodal inhibitor (SB431542), and sonic hedgehog inhibitor.

Nodal inhibitor (SB), with concentration $50 \mu \mathrm{M}$ in 1-2 cell stages, showed abnormal head and trunk (Fig.1B), whereas at $100 \mu \mathrm{M}$ a disappearance of the yolk and abnormality in the interior part of the body with short tail were observed (Fig.1C). At the dome stage of $50 \mu \mathrm{M}$, a depression of the brain was monitored, while at $100 \mu \mathrm{M}$ an observation of a smaller head and a shorter tail were detected (Fig.1D). SU inhibitor expressed a short tail 
morphology at concentration $10 \mu \mathrm{M}$ and $20 \mu \mathrm{M}$ that were exposed in 1-2cells (Fig.1E,F), additionally, all fish died at $40 \mu \mathrm{M}$ in the same stage.

Cyclopamine (shh inhibitor) caused supressed head parts and showed short body at concentrations $50 \mu \mathrm{M}$ and $100 \mu \mathrm{M}$ in 1-2cells stage and sphere stage (Fig.1G,H,I). At late gastrula stage of concentrations $5 \mu \mathrm{M}, 10 \mu \mathrm{M}$ and $20 \mu \mathrm{M}$, DM presented short tail (Fig. 1J), and all fish that were exposed to DM $5 \mu \mathrm{M}, 10 \mu \mathrm{M}$ and $20 \mu \mathrm{M}$ at 1-2 cells stages died after 24hpf from exposure.

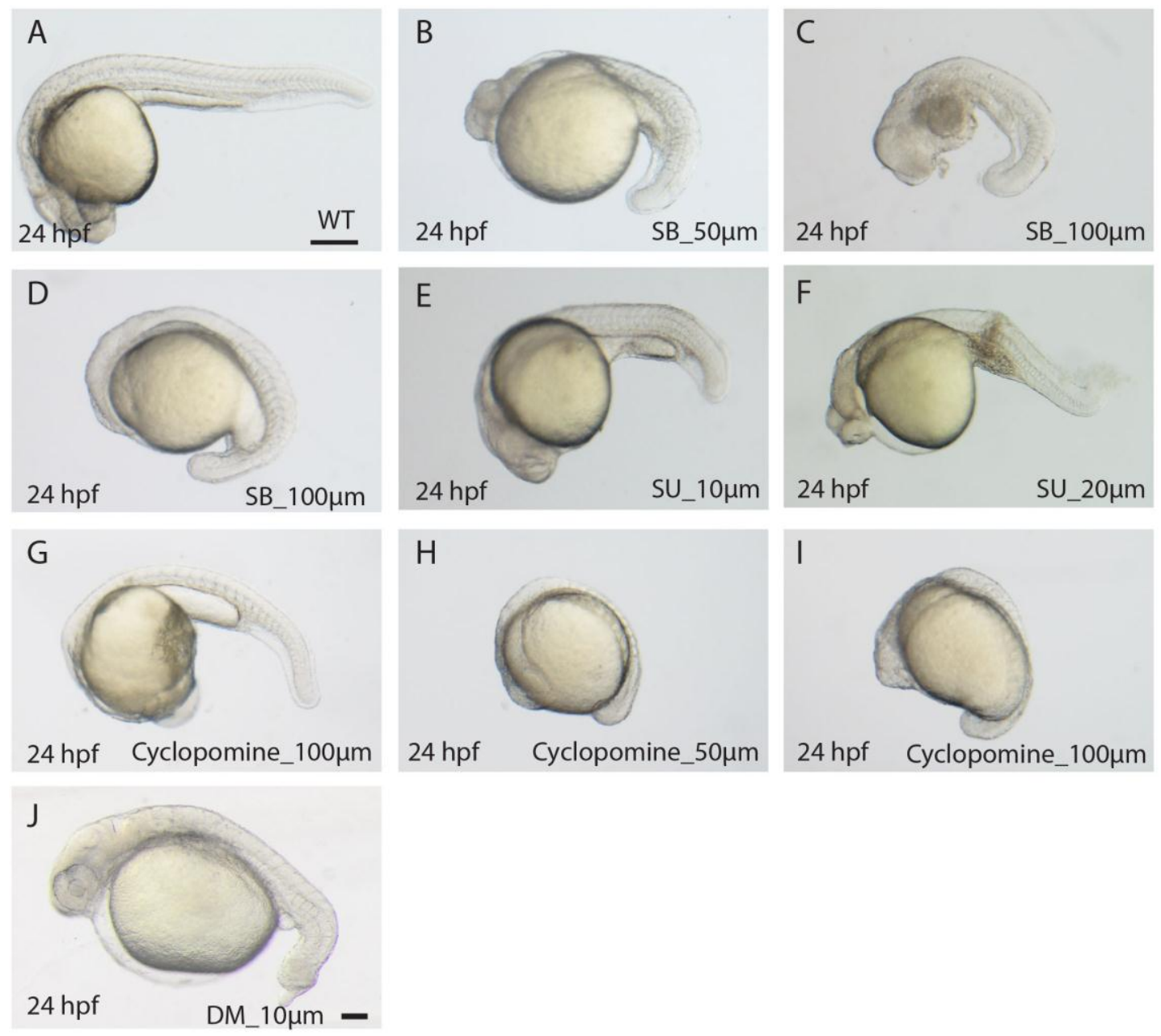

\section{Fig.1 Live embryos of $D$. rario treated with chemical inhibitors .}

A, wild type (24hpf). B, SB50 $\mu \mathrm{M}$ (24hpf). C, SB100 $\mu \mathrm{M}$ (24hpf) (B and C, embryos treated at 1 cell

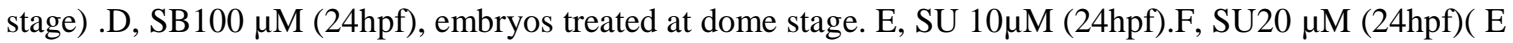
and F, embryos treated at 1 cell stage). G, Cyclopamine $100 \mu \mathrm{M}$ (24hpf) embryos treated at 1 cell stage. H, Cyclopamine 50 $\mu \mathrm{M}$ (24hpf).I, Cyclopamine100 $\mu \mathrm{M}(24 \mathrm{hpf}) . \mathrm{H}$ and I, embryos treated at sphere stage. J, DM10 $\mu \mathrm{M}(24 \mathrm{hpf})$, embryos treated at late gastrula. hpf ( hour post fertalization). The scale bar $=100 \mu \mathrm{M}$. 


\section{In situ hybridization}

The embryos of zebrafish treated with DM $(5 \mu \mathrm{M}$ and $10 \mu \mathrm{M})$ at late gastrula stage generated short tail embryo (Fig.2B, C), and DM showed deformity in the posterior part of the body at concentration $20 \mu \mathrm{M}$ at late gastrula stage (Fig.2D). Myosin light chain (myl10) stained the muscle for the embryos treated with DM at concentration $5 \mu \mathrm{M}$ and $10 \mu \mathrm{M}$, while at $20 \mu \mathrm{M}$ concentration the myl10 expression was lost and only a small part of deformed tail was stained. SB at concentration $50 \mu \mathrm{M}$ in 1-2 cell stage showed a small reduction in myllo (Fig.3B), but SB showed more reduction of the muscle at $100 \mu \mathrm{M}$ for the embryos treated at 1-2 cells stage (Fig.3C). At all concentrations of SU in both one cell stage and the $50 \%$ epiboly, myll0 showed reduction in expression (Fig.4B-E) but it was more severe at $40 \mu \mathrm{M}$ when exposed from epiboly stage (Fig.4E). Cyclopam ininhibtor reduced myllo in embryos that were treated with $50 \mu \mathrm{M}$ one cell stage (Fig.5B), whereas at $100 \mu \mathrm{M}$, myl10 no expression was detected in the embryos that were exposed at one cell stage or sephere stage (Fig.5 Cand D).

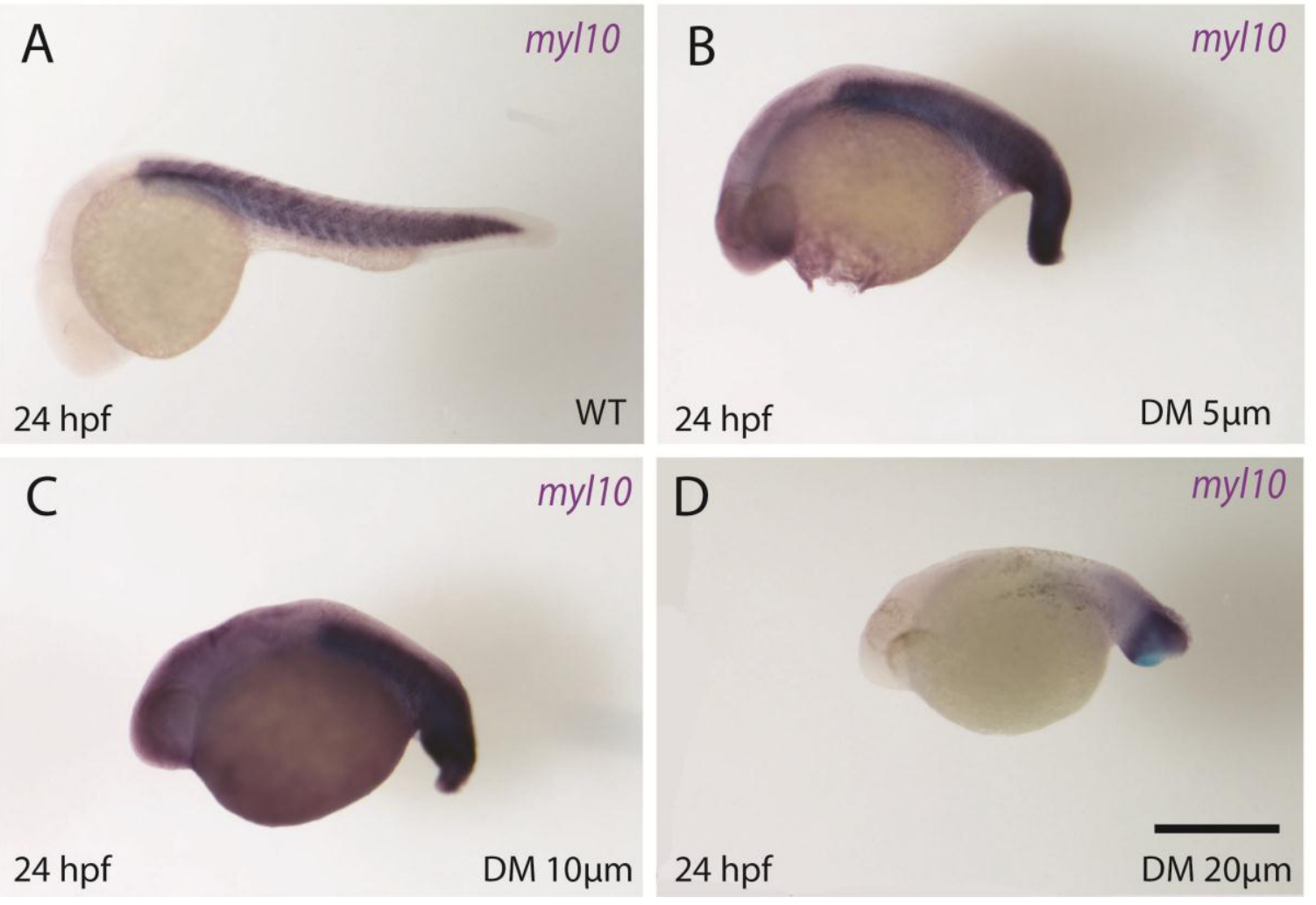

Fig.2 In situ hybridizaton with my10 of D.rerio embryos treated with DM.

A, wild type. B, DM(5 $\mu \mathrm{M})$. C, DM(10 $\mu \mathrm{M})$. D, DM(20 $\mathrm{DM})$.B-D embryos treated at late gastrula, they showed reduction of posterior part .D showed more severe in reduction of myl10. Scale bar $=100 \mu \mathrm{M}$. 


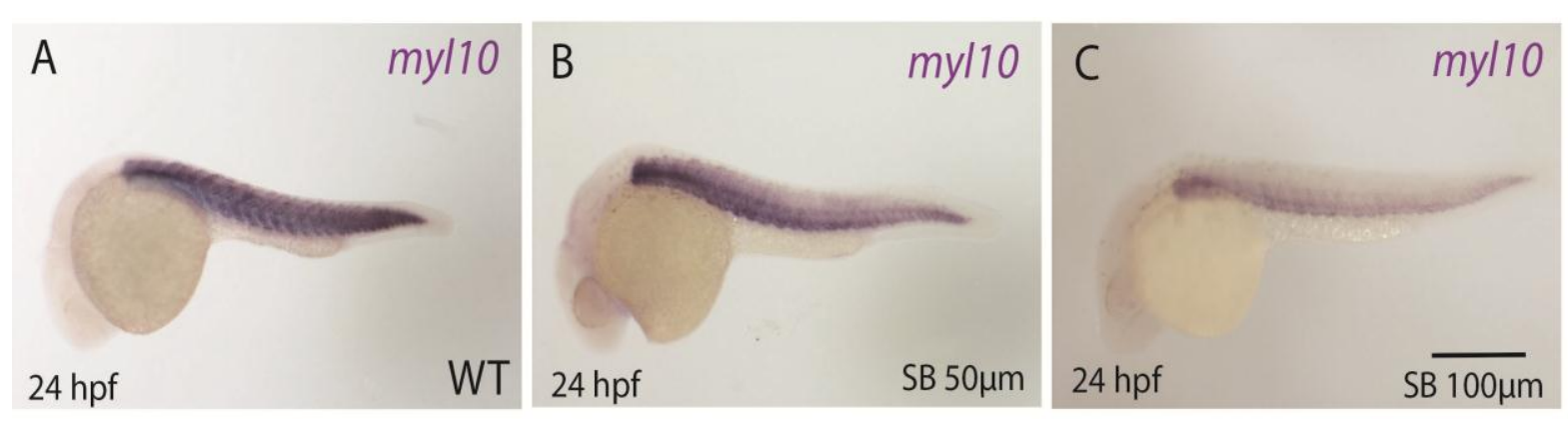

Fig. 3 In situ hybridizaton with my10 of D.rerio embryos treated with SB.

A, wild type. B, $\mathrm{SB}(50 \mu \mathrm{M})$. C, $\mathrm{SB}(100 \mu \mathrm{M})$. B and C embryos treated at the one cell stage. SB reduced the gene marker myllo in trunk and tail muscles . Scale bar $=100 \mu \mathrm{M}$.

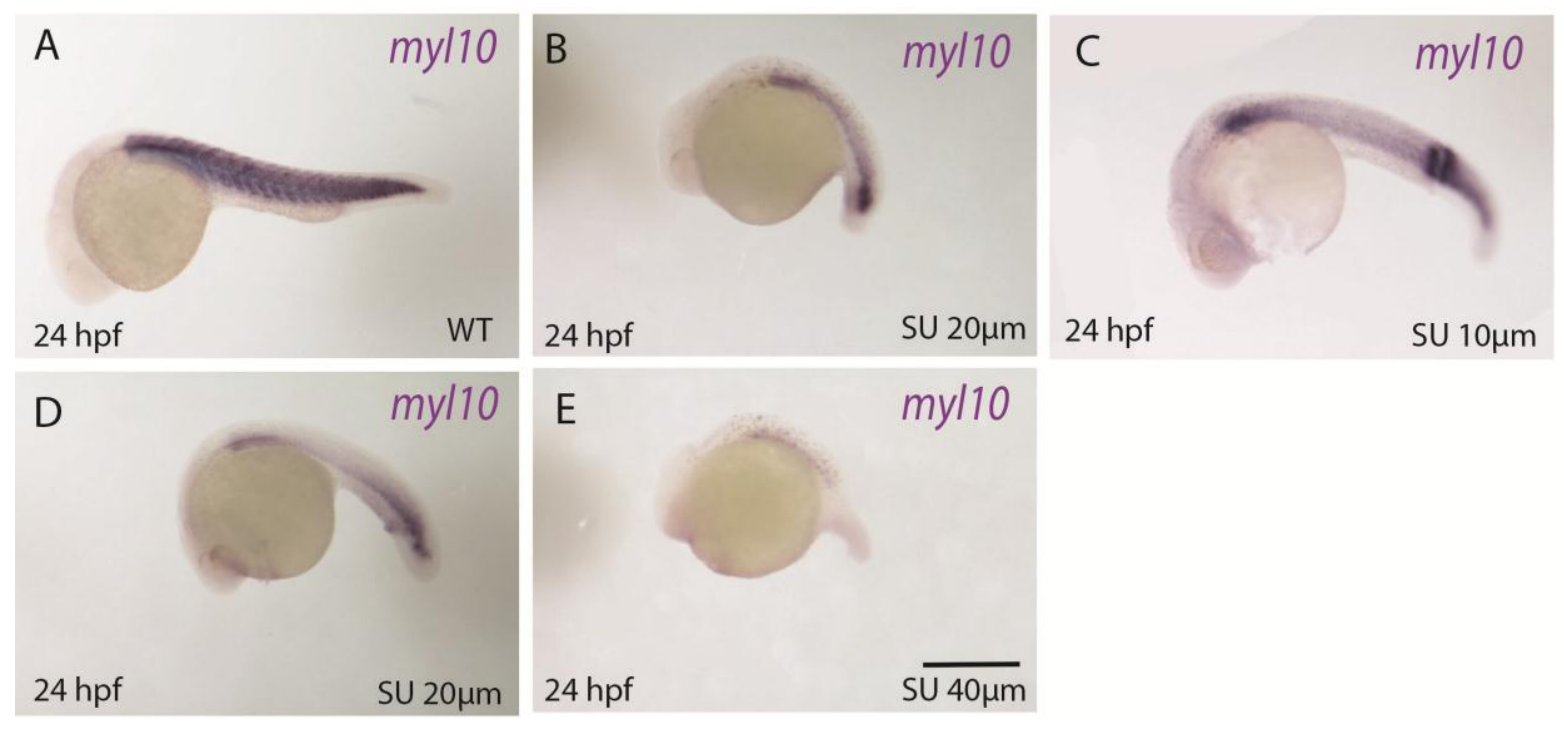

Fig.4, In situ hybridizaton with my10 of D.rerio embryos treated with SU. A, wild type. B, SU $(20 \mu \mathrm{M})$ embryos treated at 1 cell stage. C,D and $\mathrm{E} \mathrm{SU}(10 \mu \mathrm{M}, 20 \mu \mathrm{M}$ and $40 \mu \mathrm{M}$ respectively, embryos treated at $50 \%$ epiboly). B-E showed the reduction of myl10 expression with more severer in E. Scale bar $=100 \mu \mathrm{M}$. 


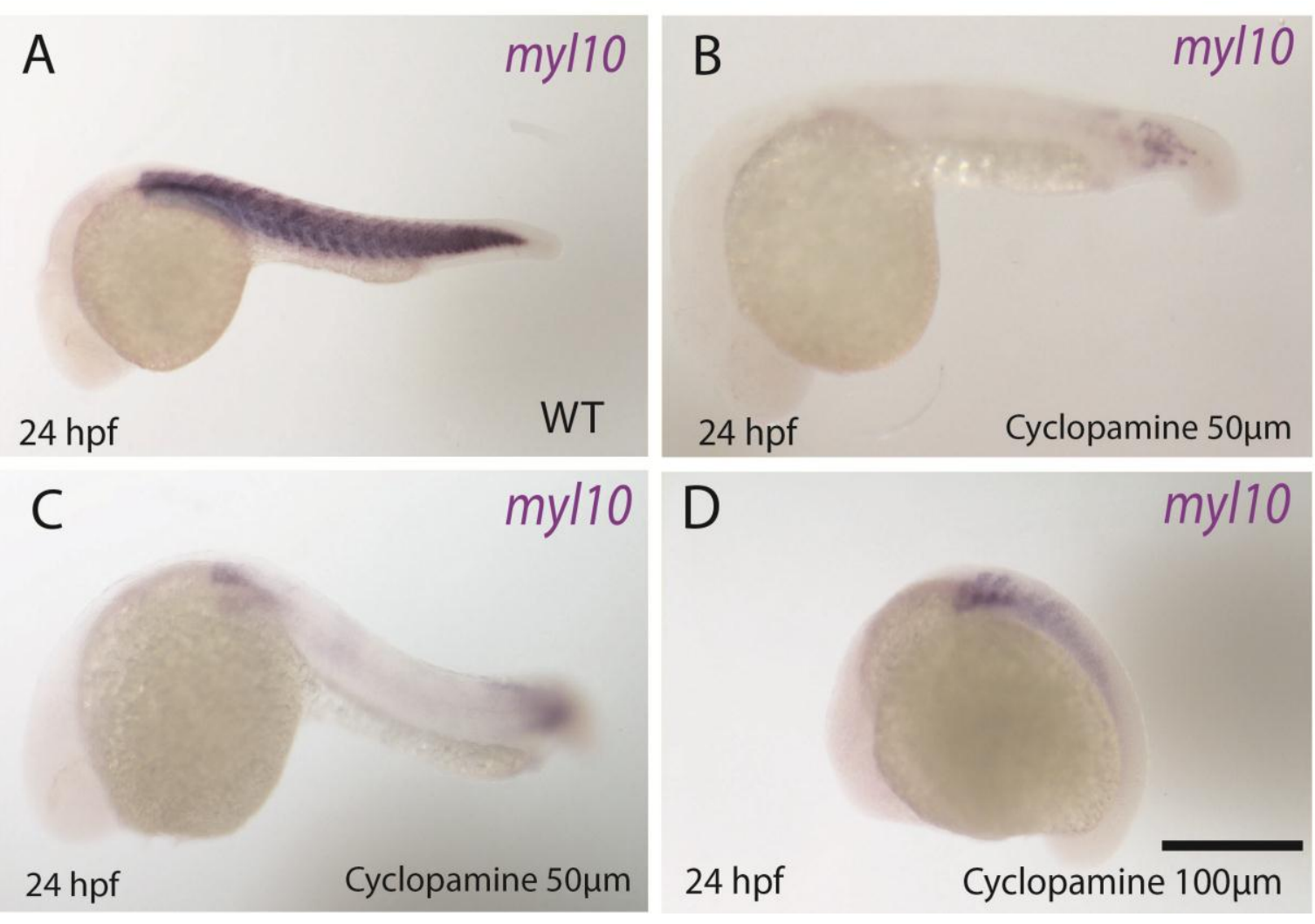

Fig.5 In situ hybridizaton with my10 of D.rerio embryos treated with Cyclopamine. A, wild type. B, Cyclopamine $(50 \mu \mathrm{M})$ embryos treated at one cell stage. C, Cyclopamine $(50 \mu \mathrm{M})$. D, Cyclopamine $(100 \mu \mathrm{M}) . \mathrm{C}$ and $\mathrm{D}$, embryos treated at sphere stage. Cyclopamine inhibitor reduced my 10 in posterior part of embryo. Scale bar $=100 \mu \mathrm{M}$

Table (1) shows concentrations of inhibitors used in experiment for embryos at the stage of treatment and the percentage of abnormal and dead embryos. These results suggest that all tested signaling pathways are somehow involved in the development of mesoderm, showing the significant role of some transcription factors in the mesoderm induction but in different ways and different parts of the embryo through a different stage of development. 
Table (1) Treatment of $D$. rerio with chemical inhibitors

\begin{tabular}{|c|c|c|c|c|c|c|}
\hline Chemical & Concentration & $\begin{array}{c}\text { Stage of } \\
\text { treatment }\end{array}$ & $\begin{array}{c}\text { Number } \\
\text { (total) }\end{array}$ & $\begin{array}{l}\text { Number } \\
\text { (dead) }\end{array}$ & $\begin{array}{c}\text { Number } \\
\text { (abnormal) }\end{array}$ & $\begin{array}{c}\% \text { of } \\
\text { abnormality }\end{array}$ \\
\hline \multirow[t]{2}{*}{ Dorsomorphin } & \multirow[t]{2}{*}{$5 \mu \mathrm{m}$} & $1-2$ cell & 15 & All dead & - & - \\
\hline & & Late gastrula & 15 & - & 15 & 100 \\
\hline \multirow[t]{2}{*}{ Dorsomorphin } & \multirow[t]{2}{*}{$10 \mu \mathrm{m}$} & $1-2$ cell & 15 & All dead & - & - \\
\hline & & Late gastrula & 15 & 12 & 3 & 20 \\
\hline \multirow[t]{2}{*}{ Dorsomorphin } & \multirow[t]{2}{*}{$20 \mu \mathrm{m}$} & $1-2$ cell & 15 & All dead & - & - \\
\hline & & Late gastrula & 15 & 9 & 6 & 40 \\
\hline \multirow[t]{2}{*}{ SU5402 } & \multirow[t]{2}{*}{$10 \mu \mathrm{m}$} & $1-2$ cell & 15 & - & 15 & 100 \\
\hline & & $50 \%$ epiboly & 15 & - & 15 & 100 \\
\hline \multirow[t]{2}{*}{ SU5402 } & \multirow[t]{2}{*}{$20 \mu \mathrm{m}$} & $1-2$ cell & 15 & - & 15 & 100 \\
\hline & & $50 \%$ epiboly & 15 & - & 15 & 100 \\
\hline \multirow[t]{2}{*}{ SU5402 } & \multirow[t]{2}{*}{$40 \mu \mathrm{m}$} & $1-2$ cell & 15 & All dead & - & - \\
\hline & & $50 \%$ epiboly & 15 & 1 & 14 & 93.33 \\
\hline \multirow[t]{2}{*}{ SB431542 } & \multirow[t]{2}{*}{$25 \mu \mathrm{m}$} & $1-2$ cell & 15 & 2 & 13 & 86.66 \\
\hline & & Dome stage & 15 & - & 15 & 100 \\
\hline \multirow[t]{2}{*}{ SB431542 } & \multirow[t]{2}{*}{$50 \mu \mathrm{m}$} & $1-2$ cell & 15 & 3 & 12 & 80 \\
\hline & & Dome stage & 15 & - & 15 & 100 \\
\hline \multirow[t]{2}{*}{ SB431542 } & \multirow[t]{2}{*}{$100 \mu \mathrm{m}$} & $1-2$ cell & 15 & 6 & 9 & 60 \\
\hline & & Dome stage & 15 & - & 15 & 100 \\
\hline \multirow[t]{2}{*}{ cyclopamine } & \multirow[t]{2}{*}{$50 \mu \mathrm{m}$} & $1-2$ cell & 15 & 4 & 11 & 73.33 \\
\hline & & Sphere stage & 15 & 2 & 13 & 86.66 \\
\hline \multirow[t]{2}{*}{ cyclopamine } & \multirow[t]{2}{*}{$100 \mu \mathrm{m}$} & $1-2$ cell & 15 & 4 & 11 & 73.33 \\
\hline & & Sphere stage & 15 & 3 & 12 & 80 \\
\hline
\end{tabular}




\section{DISCUSSION}

To use $D$. rerio as a new model species for studying the development of mesoderm, the current study was conducted to specify the role expression of some genes in early development of mesoderm induction. Thus, to attain this purpose a unique fish model was used to investagate the relationship among some genes and the early development in a relatively short time compared to other species such as Cyprinus carpio. It is clear that from the following embryonic development stages, the total period from fertilization to hatching that took 2-3 days (Kimmel et al., 1995), is considered short compared to other species like mangrove killifish Kryptolebias marmoratus recording 13 days as a hatching period (Mourabit, et al., 2011).

\section{Treatment of $D$.rario with chemical inhibitors}

To learn the roles of important signaling pathways in mesoderm development, zebrafish $D$. rerio embryos were treated with chemical inhibitors for candidate pathways. Considerably, DM is a specific inhibitor for Bmp (bone morphogenetic protein) pathway. Hence, Bmp is important for dorsal-ventral axis formation (Kudoh et al., 2004), especially that Bmp inhibitor (DM) suppressed the dorsal and ventral tissues. One possibility may be expressed is that Bmp inhibitor might suppress ventral and dorsal tissues formation and suppress the surrounding tissues that generate tail via affecting the gene activity of tail organizer. For instance, one of the zebrafish mutant that is called swirl is characterized by a reduction in the tail and epidermis due to the loss of bmp2b (Kishimoto et al., 1997). Moreover, the body axis of K.marmoratus are defected by BMP inhibitor (Mourabit et al., 2014).

Myosin protein expressed early in zebrafish, the expression of which is found present at the first day post fertilization (Saud et al.,2021). Myosin light chain (myl10), that is one of the important genes for slow muscles, is used as a marker to detect the role of mesoderm induction through inhibition of BMP. It was found that in situ hybridization supressed the posteriorir part of the body, and the deformation was more severe at concentration $20 \mu \mathrm{M}$ from late gastrula of exposure in a way that confirmed the important role of BMP during gastrulation. Since nodal and FGF are secretory protiens that induce mesoderm (Thisse \& Thisse, 2005) thus, nodal inhibitor (SB431042) was used to suppress mesoderm formation by which mesoderm derived tissue such as muscle can be reduced. Though, in situ result showed mild reduction of myllo at $50 \mu \mathrm{M}$ in one cell stage, the reduction was more significant at concentration $100 \mu \mathrm{M}$. The FgF inhibitor (SU5402) reduced spinal cord and muscle development because FGF has important role during different stages of embryonic development including one cell stage, as FgF ihhibitor was applied in one cell stage and 50\% epiboly. In one cell stage of exposure, the tail became short and myllo marker exhibited a reduction of muscles, while the severity 
was more clear in muscle reduction at concentration of $40 \mu \mathrm{M}$. These are all important signaling pathways that are essential for mesoderm development. By using specific inhibitors of those signaling pathways, the effect of these pathways on mesoderm development might be easy to investigate.

Therefore, cyclopamine (Sonic hedgehogh inhibitor) can reduce the signaling emanating from the midline around the notochord. In addition, Shh is important for specifying different somite muscle types. In the current study, cyclopamine changed the position of the muscles and reduced myllo, and the severity of defection was observed at the concentration of $100 \mu \mathrm{M}$ confirming their role in muscle induction.

The present study suggest that many signaling pathways are important in mesoderm development. However, it is possible that these pathways have crucial roles in early lineage specification (e.g. mesoderm induction). To further characterise the signaling pathways, it is needed to examine other lineage markers (e.g. fast muscle).

\section{CONCLUSION}

Many inhibitors (DM, SU, SB and Cyclopamine) were tested and concluded that these chemicals inhibit mesoderm development. Yet, further analysis using more markers and stages with specific chemical treatments are required as well as using knock down and knock out gene technique that can show deep details for the role and time expression of genes in different stages during mesoderm induction.

\section{REFERENCES}

Allen, D. L.; Sartorius, C. A. ;Sycuro, L. K. and Leinwand, L. A.(2001). Different Pathways Regulate Expression of the Skeletal Myosin Heavy Chain Genes. Journal of Biological Chemistry., 276(47): 43524-43533.

Arnold, H. H.and Braun, T. (1996). Targeted inactivation of myogenic factor genes reveals their role during mouse myogenesis: A review. International Journal of Developmental Biology., 40(1): 345-353.

Bassel-Duby, R. and Olson, E. N.( 2006). Signaling Pathways in Skeletal Muscle Remodeling. Annual Review of Biochemistry., 75(1): 19-37.

Black, B. L. and Olson, E. N. (1998). Transcriptional Control of Muscle Development By Myocyte Enhancer Factor-2 (Mef2) Proteins. Annu. Rev. Cell Dev. Biol., 14: 167-96.

Buckingham, M. (1992). Making muscle in mammals. Trends in Genetics, 8(4): 144149.

Carcamo, J.; Weis, F.M.; Ventura, F.; Wieser, R.; Wrana, J.L.; Attisano, L. and Massague, J. (1994). Type I receptors specify growth-inhibitory and transcriptional 
responses to transforming growth factor beta and activin.Mol. Cell. Biol., 14: 38103821.

Chin, E. R.; Olson, E. N.; Richardson, J. a.;Yang, Q.; Humphries, C.; Shelton, J. M. and Williams, R. S. (1998). A calcineurin-dependent transcriptional pathway controls skeletal muscle fiber type. Genes \& Development, 12(16): 2499-2509.

Coutelle, O.; Blagden, C. S.; Hampson, R.; Halai, C.; Rigby, P.W. and Hughes, S. M. (2001). Hedgehog signalling is requiredfor maintenance of myf5 and myoD expression and timely terminal differentiation in zebrafish adaxial myogenesis.Dev. Biol., 236: 136-150.

Currie, P. D. and Ingham,P.W. (1996). Induction of a specific muscle cell type by a hedgehog-like protein in zebrafish. Nature., 382: 452-455.

Dick, A.; Hild, M.; Bauer, H.; Imai, Y.; Maifeld, H.; Schier,A.; Talbot, W.; Bouwmeester ,T. and Hammerschmidt, M.( 2000). Essential role of Bmp7 (snailhouse) and its prodomain in dorsoventral patterning of the zebrafish embryo. Development., 127(2): 343-354.

Fisher, M. E.;Isaacs, H. V. and Pownall, M. E.( 2002). eFGF is required for activation of XmyoD expression in the myogenic cell lineage of Xenopus laevis. Development., 129: 1307-1315.

Gundersen, K. (2011). Excitation-transcription coupling in skeletal muscle: The molecular pathways of exercise. Biological Reviews, 86(3): 564-600.

Hammerschmidt, M.; Brook, A. and McMahon, A. P.(1997). The worldaccording to hedgehog. Trends Genet., 13: 14-21.

Kimmel C. B.; Ballard, W. W.; Kimmel, S. R.; Ullmann, B. and Schilling, T. F. (1995). Stages of embryonic development of the zebrafish. Developmental Dynamics : An Official Publication of the American Association of Anatomists., 203(3): 253-310.

Kishimoto, Y.; Lee, K. H.,; Zon, L.; Hammerschmidt, M. and Schulte-Merker, S. (1997). The molecular nature of zebrafish swirl: BMP2 function is essential during early dorsoventral patterning. Development., 124(22): 4457-4466.

Kudoh, T.; Concha, M. L.; Houart, C.; Dawid, I. B. and Wilson, S. W. (2004). Combinatorial Fgf and Bmp signalling patterns the gastrula ectoderm into prospective neural and epidermal domains, Development., 131(15): 3581-3592.

Kwon, H. J.; Bhat, N.; Sweet, E. M.; Cornell, R. A. and Riley, B. B. (2010). Identification of early requirements for preplacodal ectoderm and sensory organ development. PLoS Genetics, 6(9). 
Lee, S. T.; Welch, K. D.; Panter, K. E.; Gardner, D. R.; Garrossian, M. and Chang, C. W. T. (2014). Cyclopamine: From cyclops lambs to cancer treatment. Journal of Agricultural and Food Chemistry., 62(30):7355-7362.

Mohedas, A. H.; Xing, X.; Kelli A. Armstrong; Alex ,N.; Bullock,D. G. and Paul B. Yu. (2013). Development of an ALK2-biased BMP type I receptor kinase inhibitor Agustin. ACS Chem Biol., 8(6): 1291-1302.

Mourabit S.; Edenbrow, M.; Croft, D. P. and Kudoh, T. (2011). Embryonic development of the self- fertilizing mangrove killifish Kryptolebias marmoratus. Developmental Dynamics., 240(7): 1694-1704.

Mourabit S.;Moles,MW.;Smith,E.;Aerle,R.V.and Kudoh,T.(2014).BMP suppression in mangrove killi fish embryos causes a split in the body axis.PLos One. ,9(1).

Murone M.; Rosenthal, A. and de Sauvage, F. J.(1999).Hedgehog signal transduction: from flies to vertebrates. Exp. Cell Res., 253:25-33.

Ochi, H. and Westerfield, M. (2007). Signaling networks that regulate muscle development: Lessons from zebrafish. Development Growth and Differentiation., 49(1):1-11.

Perron M.;S. Boy, M.A.; Amato, A.; Viczian, K.; Koebernick, T.and Pieler, W. Harris.(2002).A novel function for Hedgehog signaling in retinal pigment epithelium differentiation. Development., 130: 1565-1577.

Poulain, M.; Furthuer, M.; Thisse, B.; Thisse, C. and Lepage,T.(2006).Zebra fish endoderm formation is regulated by combinatorial Nodal,Fgf and BMP signalling.Dev.,133:2189-2200.

Pownall, M. E.; Gustafsson, M. K. and Emerson, C. P.( 2002). Myogenic Regulatory Factors and the Specification of Muscle Progenitors in Vertebrate Embryos. Annual Review of Cell and Developmental Biology., 18(1):747-783.

Prykhozhij, S. V and Neumann, C. J. (2008). Distinct roles of Shh and Fgf signaling in regulating cell proliferation during zebrafish pectoral fin development. BMC Developmental Biology., 8, 91.

Rana, Z. A.; Gundersen, K. and Buonanno, A. (2008). Activity-dependent repression of muscle genes by NFAT. Proceedings of the National Academy of Sciences of the United States of America., 105(15): 5921-5926.

Ryden, M.;Imamura, T.; Jornvall, H.; Belluardo, N.; Neveu, I.; Trupp, M.;Okadome, T.; ten Dijke, P. and Ibanez, C.F.(1996). A novel type I receptor serine-threonine kinase predominantly expressed in the adult central nervoussystem. J. Biol. Chem., 271:30603-30609. 
Saud,H.A.; Alshami,I.J.J.and Cooper,R.(2021). Localization, Distribution and Structure of Muscle Fibres Using Specific Antibody Markers in the zebrafish, Danio rerio (Hamilton, 1822). Basrah J. Agric. Sci. 34(1): 147-155.

Schiaffino, S.; Sandri, M. and Murgia, M. (2007). Activity-dependent signaling pathways controlling muscle diversity and plasticity. Physiology (Bethesda)., 22:269- 278.

Thisse, B.;Thisse, C. and Weston, J. A. (1995). Novel FGF receptor (Z-FGFR4) is dynamically expressed in mesoderm and neurectoderm during early zebrafish embryogenesis. Developmental Dynamics: An Official Publication of the American Association of Anatomists., 203(3): 377-391.

Thisse, B. and Thisse, C. (2005). Functions and regulations of fibroblast growth factor signaling during embryonic development. Developmental Biology., 287(2): 390402.

Thorimbert V.;Konig,D.;Marro,J.;Ruggiero,F.and Jazwinsk,A. (2015). Bone morphogenetic protein signailing promotes morphogenesis of blood vessels wound epidermis and actiontrichu during fin regeneration in zebra fish.FASEB J.,29(10):4299-312.

Wang,H. ; Holland,P.W.H and Takahashi,T.(2019). Gene profling of head mesoderm in early zebrafsh development: insights into the evolution of cranial mesoderm. EvoDevo 10(14):1-14.

Weinberg, E. S.; Allende, M. L.; Kelly, C. S.; Abdelhamid, A.; Murakami, T.; Andermann, P. and Riggleman, B. (1996). Developmental regulation of zebrafish MyoD in wild-type, no tail and spadetail embryos. Development (Cambridge, England)., 122(1): 271-80.

Weintraub, H.; Davis, R.; Tapscort, S.; Thayer, M.; Krause, M.;Benezra, R. and Lassar, A. (1991). The myoD Gene Family: Nodal Point During Specification of the Muscle Cell Lineage. Science., 251(1987): 761-766.

Wolff, C.; Roy, S.; Ingham, P. W.; Court, F. and Sheffield, S. (2003). Multiple Muscle Cell Identities Induced by Distinct Levels and Timing of Hedgehog Activity in the Zebrafish Embryo., 13:1169-1181.

Wu, H.; Naya, F. J.; McKinsey, T. A.; Mercer, B.; Shelton, J. M.; Chin, E. R. and Williams, R. S. (2000). MEF2 responds to multiple calcium-regulated signals in the control of skeletal muscle fiber type. EMBO Journal., 19(9):1963-1973. 